\title{
Hexadecatrienoic Acid
}

National Cancer Institute

\section{Source}

National Cancer Institute. Hexadecatrienoic Acid. NCI Thesaurus. Code C68378.

A polyunsaturated long-chain fatty acid with a 16-carbon backbone and exactly 3 double bonds. There are at least 5 separate isomers that could be called by this name. 